\title{
Aprendizagem das Competências Gerais na Graduação em Psicologia
}

Aprendizaje de las Competencias Generales en Pregrado de Psicología

General Skills Learning in Psychology Undergraduate

Lívia Teixeira Costa Silva

ORCID: https://orcid.org/0000-0002-3164-0444 Faculdade INESP, São Paulo/Brasil

Luana Valeria de Souza Chagas

ORCID: https://orcid.org/0000-0001-5676-2344 Centro Universitário CESMAC, Alagoas/Brasil

Edna Pereira Gomes de Morais

ORCID: https://orcid.org/0000-0002-0034-0166 Universidade Estadual de Ciências da Saúde de Alagoas, Alagoas/Brasil

Layse Veloso de Amorim Santos

ORCID: https://orcid.org/0000-0002-9162-6919

Declaração de Direito Autoral

Centro Universitário CESMAC, Alagoas/Brasil

A submissão de originais para este periódico implica na transferência, pelos autores, dos direitos de publicação impressa e digital. Os direitos autorais para os artigos publicados são do autor, com direitos do periódico sobre a primeira publicação. Os autores somente poderão utilizar os mesmos resultados em outras publicações indicando claramente este periódico como o meio da publicação original. Em virtude de sermos um periódico de acesso aberto, permite-se o uso gratuito dos artigos em aplicações educacionais e científicas desde que citada a fonte conforme a licença CC-BY da Creative Commons.

\section{Resumo}

As competências e habilidades gerais previstas nas Diretrizes Curriculares Nacionais para os cursos de graduação em Psicologia são a base para a atuação deste profissional. Tornando relevante conhecer se ocorre o esperado desenvolvimento delas durante o curso. As DCN norteiam a formação pautada no "ensino das competências". E o psicólogo deve se relacionar com a realidade através das habilidades e competências desenvolvidas na formação. O estudo teve como objetivo verificar a presença das competências e habilidades gerais, previstas nas Diretrizes Curriculares Nacionais dos Cursos de graduação em Psicologia, em graduandos do décimo período. Sendo do formato descritivo, transversal e quantitativo. A amostra incluiu alunos do $10^{\circ}$ período e os professores que na ocasião ministravam aula para eles. A pesquisa consistiu de três etapas: questionário de autopercepção e teste psicológico IFP-II para os discentes, e questionário de percepção para os docentes. Os dados coletados evidenciaram que para a maioria da amostra investigada, na ocasião da coleta, das seis competências e habilidades gerais previstas pelas DCN, cinco não foram desenvolvidas durante a graduação, sendo que apenas a competência para Educação Permanente possivelmente está presente na maior parcela dos discentes. O presente estudo forneceu informações relevantes para a reflexão do processo ensinoaprendizagem como modificador de comportamentos e como desenvolvedor de competências essenciais para a atuação do psicólogo. Com a importância do desenvolvimento de competências na formação do psicólogo, espera-se que os resultados do estudo, subsidiem futuras melhorias no processo ensino-aprendizagem. 
Palavras-chaves: Educação baseada em competências; Aprendizagem; Psicologia.

\title{
Resumen
}

Las competencias y habilidades generales previstas en las Directrices Curriculares Nacionales para los cursos de pregrado en Psicología son la base del trabajo de este profesional. Las DCN guían la capacitación basada en "enseñanza de competencias". Y el psicólogo debe relacionarse con la realidad a través de las habilidades y competencias desarrolladas en la capacitación. El objetivo de este estudio fue verificar la presencia de competencias y habilidades generales, previstas en las Directrices Curriculares Nacionales de los cursos de pregrado de Psicología, en estudiantes del décimo período. Siendo del formato descriptivo, transversal y cuantitativo. La muestra incluyó estudiantes del $10^{\circ}$ período y los maestros que en ese momento les enseñaron. La investigación consistió en tres etapas: cuestionario de autopercepción y prueba psicológica IFP-II para estudiantes, y cuestionario de percepción para maestros. Los datos recopilados mostraron que para la mayoría de la muestra investigada, en el momento de la recolección, las seis competencias y habilidades generales previstas en las DCN, cinco no se desarrollaron durante el curso de pregrado, y solo la competencia para la Educación Permanente está posiblemente presente en la mayoría de los estudiantes. El presente estudio proporcionó información relevante para la reflexión del proceso de enseñanza-aprendizaje como un modificador de comportamiento y como desarrollador de competencias esenciales para el desempeño del psicólogo. Con la importancia del desarrollo de competencias en la formación del psicólogo, se espera que los resultados del estudio subvencionen las mejoras futuras en el proceso de enseñanzaaprendizaje.

Palabras clave: Educación basada en competencias; Aprendizaje; Psicología.

\begin{abstract}
The general skills and abilities provided in the National Curricular Guidelines for undergraduate courses in Psychology are the basis for the performance of this professional. Making it relevant to know if their expected development occurs during the course. The DCN guides the training based on "competence education". And the psychologist must relate to reality through the skills and competences developed in the training. The study aimed to verify the presence of the general skills and abilities, foreseen in the National Curricular Guidelines of the Graduation Courses in Psychology, in undergraduate students of the tenth period. Being of the format descriptive, cross-sectional, quantitative study. The sample included 10th grade students and the teachers who taught them at the time. The research consisted of three stages: self-perception questionnaire and psychological test IFPII for the students, and a questionnaire of perception for teachers. The data collected showed that for the majority of the sample investigated, at the time of collection, of the six general skills and abilities predicted by the DCN, five were not developed during graduation, and only the competence for Permanent Education is possibly present in the greater part of the students. This study provided information relevant to the reflection of the teaching-learning process as a behavior modifier and as a developer of essential competences for the psychologist's performance. With the importance of developing skills in the training of the psychologist, it is expected that the results of the study, subsidize future improvements in the teaching-learning process.
\end{abstract}

Keywords: Competency-based education; Learning; Psychology.

\section{Introdução}

O tema "Desenvolvimento de Competências em um curso de graduação em
Psicologia" tem continuamente recebido atenção e sido alvo de discussão (Bastos, Gomide, \& Borges-Andrade, 2010; Brasileiro \& Souza, 2010; Lima \& Souza, 2014; Santos, 
Kienen, Viecili, Botomé \& Kubo, 2009). Essa mobilização faz parte da reestruturação que o campo da Psicologia vem vivenciando nas últimas décadas, na busca por uma profissão mais compromissada socialmente, acreditandose que o ponto de partida é repensar os cursos de graduação (Seixas, 2014). Mas, para iniciar a compreensão do processo de ensinoaprendizagem na formação do psicólogo, é preciso levantar os resultados acadêmicos.

A formação acadêmica em Psicologia deve se dar por meio do processo de aprendizagem, portanto, para estudá-la em seus alcances quanto às transformações de comportamento profissional, é essencial abordar como ocorre o processo ensinoaprendizagem. Kubo e Botomé (2001) destacam que ensino e aprendizagem são interdependentes. Enquanto o ensinar está relacionado ao fazer do professor, o aprender refere-se ao comportamento do aluno como consequência desse ensino. Considerando que o aprender é proveniente ao ensinar, a não ocorrência do aprender em decorrência do ensinar, de forma sistemática, prejudica os resultados do processo de aprendizagem, invalidando-o. O que demonstra a relevância de entender os processos de ensino-aprendizagem e seus efeitos, para que seja possível ampliar as chances de alcance dos objetivos educacionais.

Conhecer os resultados do processo ensino-aprendizagem, no universo da graduação em Psicologia, é contribuir para a formação de um profissional crítico, reflexivo, capaz de problematizar e contextualizar sua prática. Já que ele estará munido de referenciais valiosos, que permitirá a compreensão da complexidade e seus determinantes presentes no seu cotidiano (Brasileiro \& Souza, 2010). Assim, destaca-se que essa formação necessita preparar o psicólogo para responder as demandas sociais, tanto individualmente quanto coletivamente, para promover ao sujeito a garantia de sua autonomia (Conselho Federal de Psicologia [CFP], 2013). Portanto, a graduação em Psicologia requer que seja desenvolvida nos profissionais: a articulação da teoria com a prática, a compreensão histórica e social da Psicologia, e o compromisso social. O que exige que a aprendizagem ocorra de maneira coletiva e contextualizada (Ferrarini, Camargo, Albanese, Pan, \& Bulgacov, 2016).

Após décadas de análises e debates sobre o perfil do psicólogo, que ocorreram impulsionadas pelas transformações políticas no Brasil (Seixas, 2014), em 2004, foram instituídas as Diretrizes Curriculares Nacionais (DCN) para os cursos de graduação em Psicologia, em substituição ao currículo mínimo que vigorava até então (Bastos et al., 2010; Ferrarini et al., 2016). O currículo mínimo estava centrado no ensino de conteúdos objetivando uma formação tecnicista, sem consideração das questões sociais (Seixas, 2014). Já as Diretrizes Curriculares orientam que a academia aproxime a profissão da realidade, determinando que os futuros profissionais possam realmente atender às necessidades da sociedade (CFP, 2013; Santos et al., 2009).

A Resolução $n^{\circ} 8$ do Conselho Nacional de Educação (2004), institui as Diretrizes Curriculares Nacionais para os cursos de graduação em Psicologia que devem orientar as instituições de ensino superior em todo o país. Estabelecendo uma base fundamentada para fornecer o rumo do curso, além de buscar permitir a formação de um profissional voltado para atuação, pesquisa e ensino da Psicologia.

Em 2011, foi então publicada a Resolução $\mathrm{n}^{\circ} 5$ do Conselho Nacional de Educação que, apesar de revogar a Resolução $\mathrm{n}^{\mathrm{o}} 8$ de 2004, manteve praticamente inalterado o texto original, apenas ampliando o Artigo 13, que versa sobre a Formação de Professores de Psicologia como projeto pedagógico complementar e diferenciado, e modificando o Artigo 26 que trata da revogação da resolução anterior (Conselho Nacional de Educação [CNE], 2004, 2011).

Essas diretrizes são centradas na
aprendizagem em uma concepção
construtivista, e nelas está definido que cada
graduando em Psicologia adquira durante o
curso competências e habilidades gerais,
comuns a todos os profissionais da área de


saúde, essenciais para a atuação dentro de um conceito de clínica ampliada através das premissas estabelecidas pelos princípios do Sistema Único de Saúde (Conselho Federal de Psicologia [CFP], 2018), que seriam aptidões para: desenvolvimento de ações de atenção à saúde; tomada de decisões; comunicação acessível e ética; posição de liderança; administração e gerenciamento de processos; e aprendizagem contínua. Este conjunto, disposto no Artigo 4 das Resoluções, direciona os objetivos para a formação no país, que deve favorecer aos discentes o conhecimento necessário para exercer as competências e habilidades dentro da atuação na profissão do psicólogo (CNE, 2004, 2011).

Sendo assim, as competências precisam ser desenvolvidas na formação desse estudante, para que em sua prática ele seja capaz de dominar conhecimentos relacionados à Psicologia, e saber aplicá-los conforme as diferentes situações em que esteja inserido, possibilitando-o promover bons resultados (CNE, 2004, 2011). E, para isso, é imprescindível saber se relacionar com a sua realidade a partir das habilidades e competências que supostamente tenha desenvolvido durante sua formação (Kubo \& Botomé, 2001).

Mesmo que as DCN possuam eixos estruturantes e competências pré-estabelecidas, os cursos tem flexibilidade para explorar a diversidade da Ciência Psicológica de acordo com o contexto em que esteja inserido (Seixas, 2014). Considerando a multiplicidade e diversidade da Psicologia, as diretrizes propõe a valorização do diverso ao mesmo tempo em que integra e articula. De modo que as diversas possibilidades metodológicas da profissão sejam reconhecidas como ferramentas de atuação em diferentes contextos, tendo como prerrogativa a compreensão da multidimensionalidade dos fenômenos psicológicos que necessitam ser abordados em sua integralidade (Ferrarini et al., 2016).

O processo de formação de psicólogos acaba gerando, muitas vezes, incertezas e inquietações relacionadas, dentre várias questões, à falta de capacitação profissional ainda na universidade, à empregabilidade, como também à aplicabilidade dos conhecimentos (Lima \& Souza, 2014). As Diretrizes Curriculares Nacionais em Psicologia surgem na tentativa de suprir de alguma forma esses questionamentos, fornecendo um norte para a formação por meio do "ensino das competências" (Santos et al., 2009).

O "ensino de competências" fundamenta-se na compreensão de que para formar profissionais de Psicologia que estejam preparados para atender sua função social, e promover a mudança social por meio da ciência, é imprescindível que a construção desse conhecimento ocorra por meio da experiência (Ferrarini et al., 2016) de uma prática reflexiva que desenvolva nos graduandos as competências necessárias para uma atuação que, utilizando as evidências científicas, possa sempre transformar-se contingencialmente. Assim, é essencial que os discentes tenham um papel mais ativo em seu processo ensino-aprendizagem. O objetivo é que eles, com o desenvolvimento das competências, aprendam a aprender permanentemente, através do uso de metodologias ativas inseridas o mais precocemente possível em diversos contextos sociais (Poppe \& Batista, 2012).

Os termos "competência" e "habilidade", amplamente utilizados dentro do texto da resolução, necessitam ter seus conceitos melhor estabelecidos, devido a pluralidade de sentidos que ambos absorvem dentro da comunidade acadêmica, o que pode dificultar a compreensão do processo de ensino-aprendizagem dentro da formação em Psicologia (Santos et al., 2009). Assim, considera-se o conceito de "habilidade" como o "saber fazer", e através dela a competência se realiza. Já o conceito de "competência" adotado a considera como a combinação de conhecimentos, habilidades e atitudes exercidos em determinados contextos, integrando assim "o saber", "o saber fazer" e "o saber ser", resultando no "ser capaz de". A opção por esses conceitos se dá por 
sintetizarem a melhor abordagem dentro do contexto educacional, demonstrando-se construtivista (Lima \& Souza, 2014). Deste modo, fica claro como é imprescindível que os acadêmicos dos cursos de Psicologia do país "sejam capazes de", o que se pretende por meio do desenvolvimento dessas competências e habilidades.

Porém, é preciso ir além para superar o modelo de "ensino de conteúdos" e produzir resultados significativos (Santos et al., 2009). Pois, de acordo com estudos realizados, na atuação do profissional de Psicologia ainda estão sendo desconsiderados os sujeitos das demandas e existe uma grande defasagem entre as competências necessárias e aquelas que realmente estão sendo adquiridas durante as formações (Bastos et al., 2010; CFP, 2013). Atualmente, ainda é predominante um afastamento entre o meio acadêmico e as questões psicossociais, por conta da flagrante desarticulação entre ciência e profissão, inclusive com a carência do uso da pesquisa como estratégia de ensino-aprendizagem. O que ocasiona nos discentes uma percepção de que a graduação está voltada apenas para a teoria, ignorando a prática profissional (Ferrarini et al., 2016).

Ao considerar que as Diretrizes Curriculares Nacionais (DCN) para os cursos de graduação em Psicologia fundamentam o Projeto Pedagógico do curso universitário para futuros psicólogos, surge então o interesse em saber se essa estrutura de cinco anos presenciais e vivenciais está realmente formando os profissionais de acordo com o que preconiza as DCN para os Cursos de Psicologia. Tal inquietação motivou a seguinte pergunta de pesquisa: "Os alunos formandos de um curso de graduação em Psicologia possuem as competências e habilidades gerais propostas pelas Diretrizes Curriculares Nacionais para formação do Psicólogo?". Partindo do pressuposto de que as competências e habilidades gerais previstas na Resolução $\mathrm{n}^{\circ}$ 08/2004 seriam a base para a atuação do profissional de Psicologia, tornasse relevante conhecer se está ocorrendo o esperado desenvolvimento delas durante o curso (CNE, 2004).

Alguns estudos foram desenvolvidos com o intuito de analisar a formação dos psicólogos baseados nas DCN (Brasileiro \& Souza, 2010; Ferrarini et al., 2016; Poppe \& Batista, 2012). Portanto, o estudo aqui presente contribui para essa discussão, quando inova ao buscar conhecer os resultados do processo ensino-aprendizagem, em relação ao desenvolvimento das competências e habilidades gerais, por meio de uma investigação sistemática com a utilização de instrumentos científicos e psicológicos. Já que esse conhecimento pode subsidiar a melhoria de estratégias educativas promotoras do desenvolvimento destas competências e habilidades. Assim, esperou-se investigar a hipótese de que os alunos que estão finalizando o curso possuem essas competências e habilidades gerais.

Deste modo, o presente trabalho teve o objetivo de verificar a presença das competências e habilidades gerais, previstas nas Diretrizes Curriculares Nacionais dos Cursos de graduação em Psicologia, em graduandos do décimo período de uma instituição de ensino superior privada.

A pertinência do estudo é aumentada tendo em vista que, após 15 anos da publicação, recentemente esteve em curso um processo nacional de revisão das DCN para os cursos de graduação em Psicologia, intitulado de "Ano da Formação em Psicologia - 2018", organizado pelo Conselho Federal de Psicologia (CFP), pela Associação Brasileira de Ensino em Psicologia (ABEP) e pela Federação Nacional de Psicólogos (FENAPSI). O processo objetivou a construção coletiva de minuta de novas Diretrizes Curriculares Nacionais para os cursos de graduação em Psicologia, para ser encaminhada ao Conselho Nacional de Saúde e ao Conselho Nacional de Educação (CFP, 2018).

Método 
Trata-se de um estudo descritivo, transversal, de abordagem quantitativa. $\mathrm{O}$ mesmo foi aprovado pelo Comitê de Ética em Pesquisa (CEP) do Centro Universitário CESMAC, sob parecer $\mathrm{n}^{\circ} 2775514 / 2018$, estando de acordo com a Resolução 466/12 e Resolução 510/16 do CNS.

Todos os participantes receberam informações a respeito dos objetivos do estudo e assinaram o Termo de Consentimento Livre e Esclarecido (TCLE) antes de iniciar a pesquisa. A amostra foi composta por estudantes e professores de um Curso de Bacharelado em Psicologia de uma instituição privada de ensino superior de Alagoas. Foram incluídos estudantes que estivessem cursando o décimo período do curso e professores que estivessem ministrando aulas para eles nesse período, com idade acima de 18 anos, sem restrições quanto ao gênero e etnia. Foram excluídos os estudantes desperiodizados que não concluiriam a grade curricular no semestre vigente.

Os procedimentos para o desenvolvimento da presente pesquisa ocorreram em três etapas: 1 . caracterização da amostra e levantamento do perfil quanto às competências e habilidades gerais apresentadas pelos estudantes, por meio da aplicação do questionário de autopercepção quanto às competências e habilidades gerais conforme Resolução 08/2004 - DCN do Curso de Psicologia; 2. aplicação com os discentes do teste psicológico Inventário Fatorial de Personalidade (IFP-II) e 3. aplicação do questionário de percepção dos docentes quanto às competências e habilidades gerais dos alunos do $10^{\circ}$ período conforme Resolução 08/2004 DCN do Curso de Psicologia (CNE, 2004).

A amostra contou com a participação de 57 discentes. Havia um total de oito docentes ministrando disciplinas no referido período e todos eles foram incluídos na pesquisa, sendo o convite realizado individualmente.

$\mathrm{Na}$ aplicação do questionário de autopercepção do discente, os alunos foram orientados a responder um questionário contendo perguntas de autopercepção quanto às competências e habilidades gerais relacionadas as DCN do Curso de Psicologia. O mesmo marcou uma opção para cada questão, obedecendo uma escala de Likert de cinco pontos, os quais correspondem: 1 - Não desejo responder, 2 - Discordo totalmente, 3 Discordo, 4 - Concordo, 5 - Concordo totalmente. Além de questões específicas, o questionário apresentou inicialmente um levantamento de informações sociodemográficas dos sujeitos, como sexo, idade, formação anterior e ocupação.

O teste psicológico Inventário Fatorial de Personalidade (IFP-II) é validado pelo Conselho Federal de Psicologia e tem como objetivo avaliar o indivíduo em treze necessidades ou motivos psicológicos, sendo eles: assistência, intracepção, afago, autonomia, deferência, afiliação, dominância, desempenho, exibição, agressão, ordem, persistência e mudança (Leme, Rabelo, \& Alves, 2013).

Como o IFP-II é composto por cem itens, cada um relacionado a uma das treze necessidades ou motivos psicológicos, que devem ser avaliados pelos respondentes com a escala de 1 a 7 , sendo 1 o mais longe da descrição de uma necessidade frequente do avaliado e 7 o mais próximo, então, por meio dele, foi possível identificar as principais necessidades ou motivos psicológicos presentes na personalidade de cada discente.

Já que oito dessas necessidades ou motivos psicológicos (Assistência, Intracepção, Dominância, Desempenho, Agressão, Ordem, Mudança e Autonomia) possuem influência sobre as competências e habilidades gerais previstas na DCN do Curso de Psicologia, por meio da aplicação do teste houve a obtenção de informações em relação às características dos discentes quanto às competências e habilidades gerais.

Na etapa de aplicação do questionário de percepção do docente, os professores foram orientados a responder um questionário que tinha o intuito de coletar dados a respeito da 
percepção dos docentes em relação à existência ou não das competências e habilidades gerais nos alunos. $\mathrm{O}$ mesmo foi convidado a marcar uma opção para cada questão, obedecendo uma escala de Likert de cinco pontos, os quais corresponde: 1 - Não desejo responder, 2 Discordo totalmente, 3 - Discordo, 4 Concordo, 5 - Concordo totalmente. Além de questões específicas, o questionário apresentou inicialmente um levantamento de informações sociodemográficas dos sujeitos, como sexo, idade, formação e especialização.
Por conta da análise comparativa entre os dados coletados pelos questionários e pelo teste psicológico IFP-II, torna-se relevante que sejam esclarecidos os conceitos das oito necessidades ou motivos psicológicos que foram utilizados do IFP-II, considerados como prerrogativas ou oposições às competências e habilidades gerais almejadas, e, também, os conceitos das competências e habilidades gerais previstas nas DCN. O que se espera com o Quadro 1.

Quadro 1

Conceitos das Necessidades ou Motivos Psicológicos do IFP-II e das Competências e Habilidades Gerais previstas nas DCN

\begin{tabular}{ccc} 
Necessidades ou Motivos Psicológicos - IFP- & $\begin{array}{c}\text { Parâmetro de } \\
\text { comparação }\end{array}$ & $\begin{array}{c}\text { Competências e Habilidades Gerais - } \\
\text { II (Leme et al., 2013) }\end{array}$ \\
\hline
\end{tabular}

\begin{tabular}{|c|c|c|}
\hline $\begin{array}{l}\text { Assistência: Expressam os desejos e os } \\
\text { sentimentos de piedade, compaixão e ternura, } \\
\text { por meio dos quais o indivíduo deseja ser } \\
\text { simpático e gratificar as necessidades do sujeito } \\
\text { indefeso, defendê-lo no perigo, dar suporte } \\
\text { emocional e consolo na tristeza, doença e outros } \\
\text { infortúnios. }\end{array}$ & $\begin{array}{l}\text { Pré-requisito para } \\
\text { Atenção à Saúde }\end{array}$ & $\begin{array}{l}\text { Atenção à Saúde: Estão aptos a desenvolver } \\
\text { ações de prevenção, promoção, proteção e } \\
\text { reabilitação da saúde psicológica e } \\
\text { psicossocial, em nível individual e coletivo, } \\
\text { com altos padrões de qualidade e dos } \\
\text { princípios da ética/bioética. }\end{array}$ \\
\hline
\end{tabular}

Intracepção: Tendem a deixar se conduzir por sentimentos, fantasias, imaginação e introspecção. Faz julgamentos sem considerar os fatos concretos. Julga por meio de reais ou supostas intenções, valorizando-as acima dos atos em si. É pouco prático e parcial em suas opiniões.
Tomada de Decisão: Têm capacidade de Oposto da Tomada avaliar, sistematizar e decidir as condutas de Decisão mais adequadas, baseadas em evidências científicas.
Dominância: Expressam sentimentos de autoconfiança e o desejo de controlar os outros, influenciar ou dirigir o comportamento deles por meio de sugestão, sedução, persuasão ou comando.

Autonomia: Não gostam de executar tarefas impostas pela autoridade, pois gostam de agir independentemente. Resiste à coerção.
Comunicação: Devem ser acessíveis e manter os princípios éticos no uso das informações a eles confiadas, na interação com outros profissionais de saúde e o público em geral.
Para a Liderança é Liderança: No trabalho em equipe necessário que esteja em equilíbrio multiprofissional, estão aptos para assumirem posição de liderança, tendo em vista o bem da comunidade. 
Desempenho: Tendem a capacidade de atitudes ativas na busca de objetivos, com dedicação e detalhismo. Podem desenvolver tarefas simultaneamente, planejando os passos para atividades complexas e desafiantes. Tomam iniciativa das atividades que exercem, de forma assertiva e proativa.

Pré-requisito para Administração e Gerenciamento

Ordem: Tendem a pôr as coisas em ordem, manter limpeza, organização, equilíbrio e precisão.
Administração e Gerenciamento: Aptos a tomar iniciativas, fazer gerenciamento e administração de força de trabalho, dos recursos físicos e materiais e de informação. Além de estarem aptos a serem empreendedores, gestores, empregadores ou líderes nas equipes de trabalho.
Mudança: Desligam-se do que é rotineiro e fixo. Busca ativa de situações de interações sociais e atividades grupais. Pessoas assertivas com clareza de seus objetivos, especialmente em atividades complexas e desafiadoras.
Pré-requisito para

Educação Permanente
Educação Permanente: Capazes de aprender continuamente, tanto na formação, quanto na prática e ter compromisso com sua educação e o treinamento das futuras gerações. Estimulando e desenvolvendo a mobilidade acadêmica e profissional, a formação e a cooperação.
Os dados coletados foram armazenados em planilha eletrônica Excel, protegidos por senha e com permissão de acesso apenas para as pesquisadoras envolvidas na pesquisa. Foi realizada análise estatística descritiva dos dados e os resultados estão apresentados em forma de tabelas e gráficos.

\section{Resultados}

A amostra estudada foi composta de 57 estudantes, sendo $42(73,7 \%)$ do sexo feminino e $15(26,3 \%)$ do sexo masculino, com média de idade de 27,7 anos. Dos discentes, 34 (60,7\%) trancaram ou reprovaram alguma disciplina na graduação em psicologia, $6(10,5 \%)$ possuem graduação anterior e $30(52,6 \%)$ trabalham, sendo que destes $13(43,3 \%)$ trabalham em horário integral.

Já os docentes apresentaram média de idade de 48,5 anos, tempo de docência em graduação de Psicologia em média de 11,6 anos, sendo 06 do sexo feminino e 02 do sexo masculino. Entre os docentes do $10^{\circ}$ período, $100 \%$ são psicólogos e possuem pósgraduação. Com relação a área de especialização, 4 dos respondentes afirmaram atuar com Psicologia e Processos Educativos, 3 com Psicologia Organizacional e do Trabalho e 2 com Psicologia Clínica, sendo que dois afirmaram ser especializados em mais uma área.

A Tabela 1, apresenta a descrição dos resultados para os questionários de autopercepção e de percepção, destacando a informação para o total de sujeitos que desejaram não responder alguma questão específica referente às competências. A competência Administração e Gerenciamento, bem como Tomada de Decisão, foram as mais prevalentes entre os estudantes como não interessados em responder.

Tabela 1

\section{Discentes que desejaram não responder}

\begin{tabular}{lcccc}
\hline \multicolumn{1}{c}{ Competências Gerais } & \multicolumn{2}{c}{ Discente } & \multicolumn{2}{c}{ Docente } \\
& n & \% & n & \% \\
\hline Atenção à Saúde & 0 & - & 1 & 12,5 \\
Tomada de Decisão & 5 & 8,8 & 0 & - \\
Comunicação & 1 & 1,8 & 0 & - \\
Liderança & 3 & 5,3 & 0 & - \\
Administração e Gerenciamento & 6 & 10,5 & 0 & - \\
Educação Permanente & 1 & 1,8 & 0 & - \\
\hline
\end{tabular}

Legenda: $\mathrm{n}=$ número; $\%$ = percentual 
Os motivos para a não resposta não foram investigados, mas o resultado desperta a reflexão se os alunos não haviam pensado sobre essas características pessoais anteriormente. Assim, é possível que as DCN e as competências previstas nela precisem ser mais propagadas dentro da graduação, até para informar aos discentes qual os principais objetivos pretendidos com a sua formação.
Partindo dos conceitos das Competências (DCN) e das Motivações (IFPII), e definidos os parâmetros de análise, é possível começar o comparativo entre as respostas dadas pelos discentes e docentes e o que foi coletado com o teste IFP-II. A análise é iniciada por meio da Figura 1 e da Figura 2 que trazem os resultados obtidos para a competência Atenção à Saúde e para a necessidade Assistência.

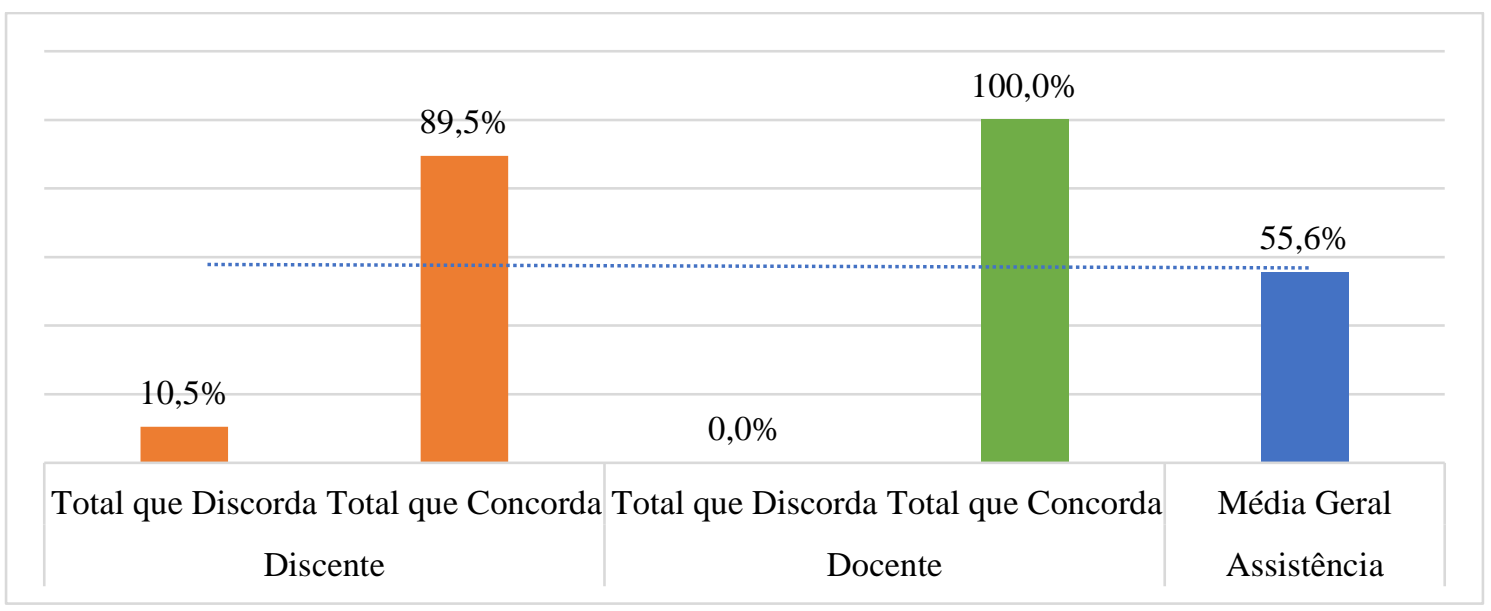

Figura 1. Comparativo referente à Competência Atenção à Saúde

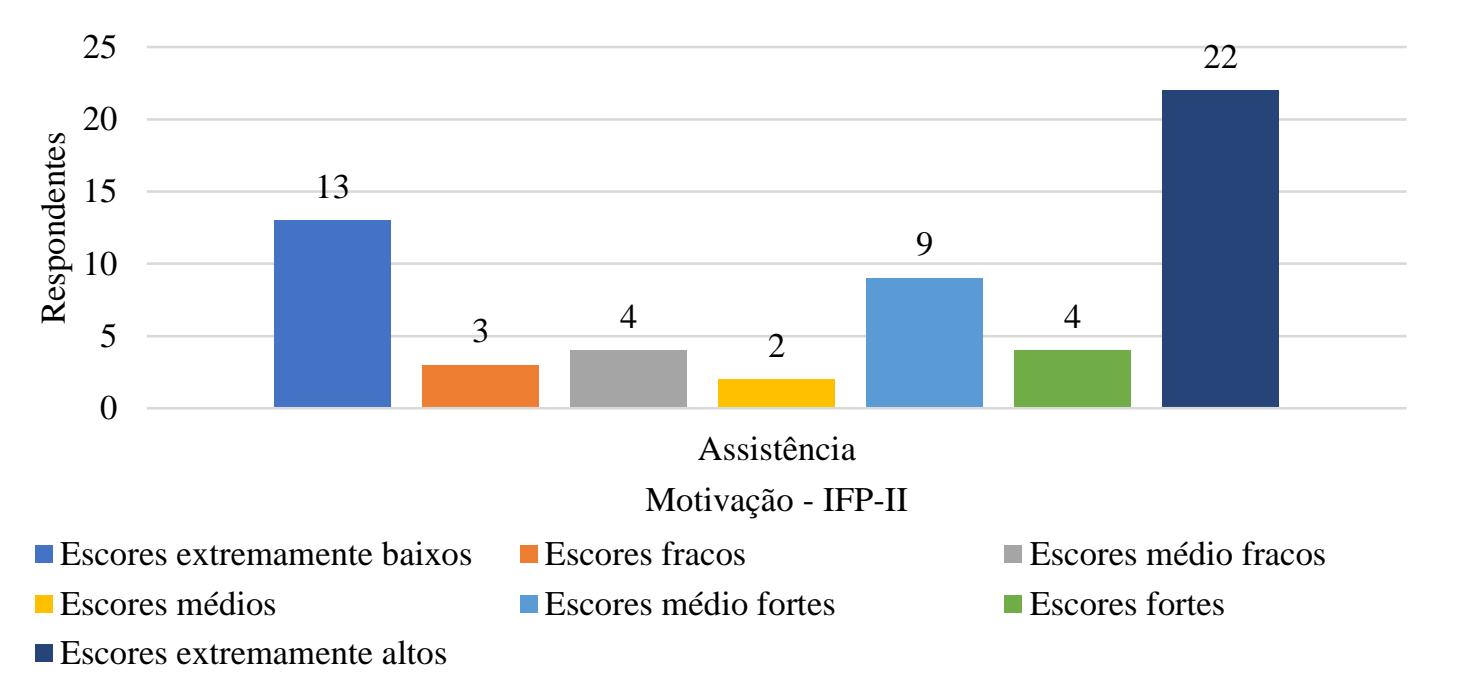

Figura 2. Resultados da Necessidade Assistência agrupados pelos Escores

Como pode ser visto na Figura 1, a grande maioria dos docentes e discentes concorda com a posse da competência de Atenção à Saúde. Entretanto, a necessidade Assistência, que é um comportamento de prérequisito para a competência Atenção à Saúde, atinge um escore em média de $55,6 \%$ para os 57 discentes investigados. Como pré-requisito, é desejável que seus resultados estivessem concentrados entre os escores médio fortes e os escores extremamente altos, como a Figura 2 demonstra que ocorreu. Porém, é possível visualizar que treze respondentes praticamente não apresentaram essa necessidade o que ocasionou uma grande diminuição na média geral. Considerando a Assistência como uma característica que faz o sujeito ir ao encontro do outro, torna-se essencial no que diz respeito à 
prevenção, promoção, proteção e reabilitação da saúde psicológica e psicossocial. É preciso que o profissional de Psicologia atue na produção de saúde desde a consideração da saúde integral, que se articula na territorialidade independentemente do tipo de instituição em que opere. E, para tanto, ele necessita sair de seu individualismo para ir ao encontro do outro (CNE, 2004; Giacomozzi, 2012). Essa competência também se articula com a de Tomada de Decisão como pode ser visto nas Figuras 3 e 4.

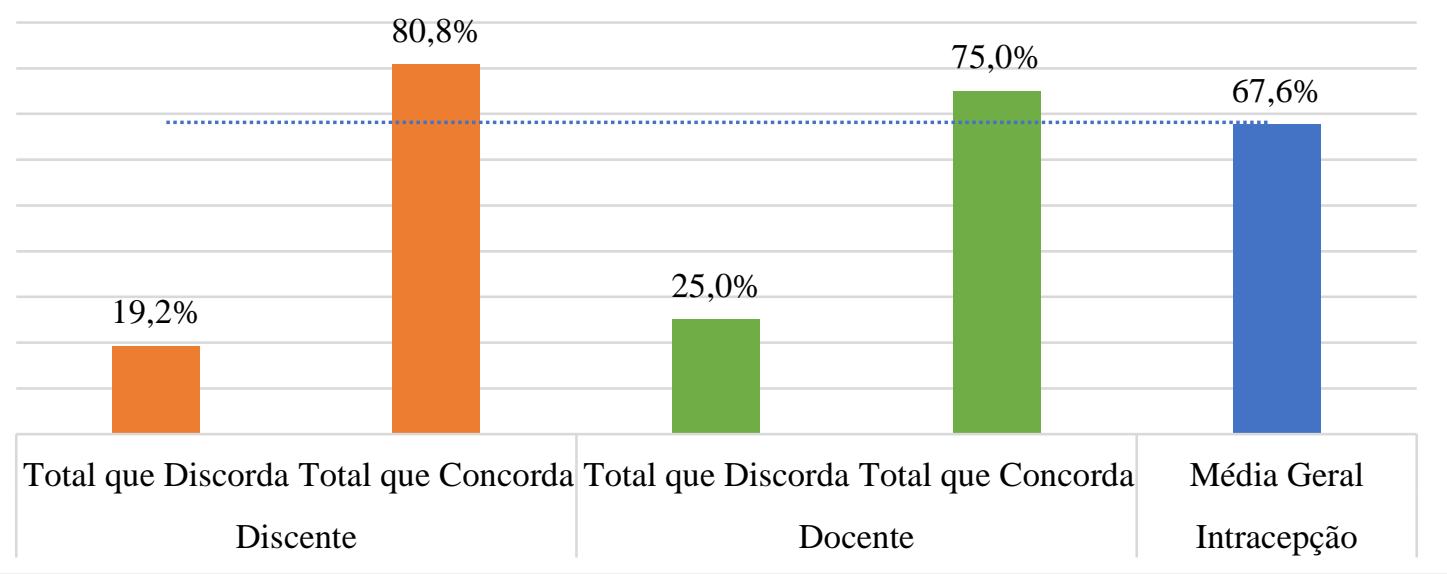

Figura 3. Comparativo referente à Competência Tomada de Decisão

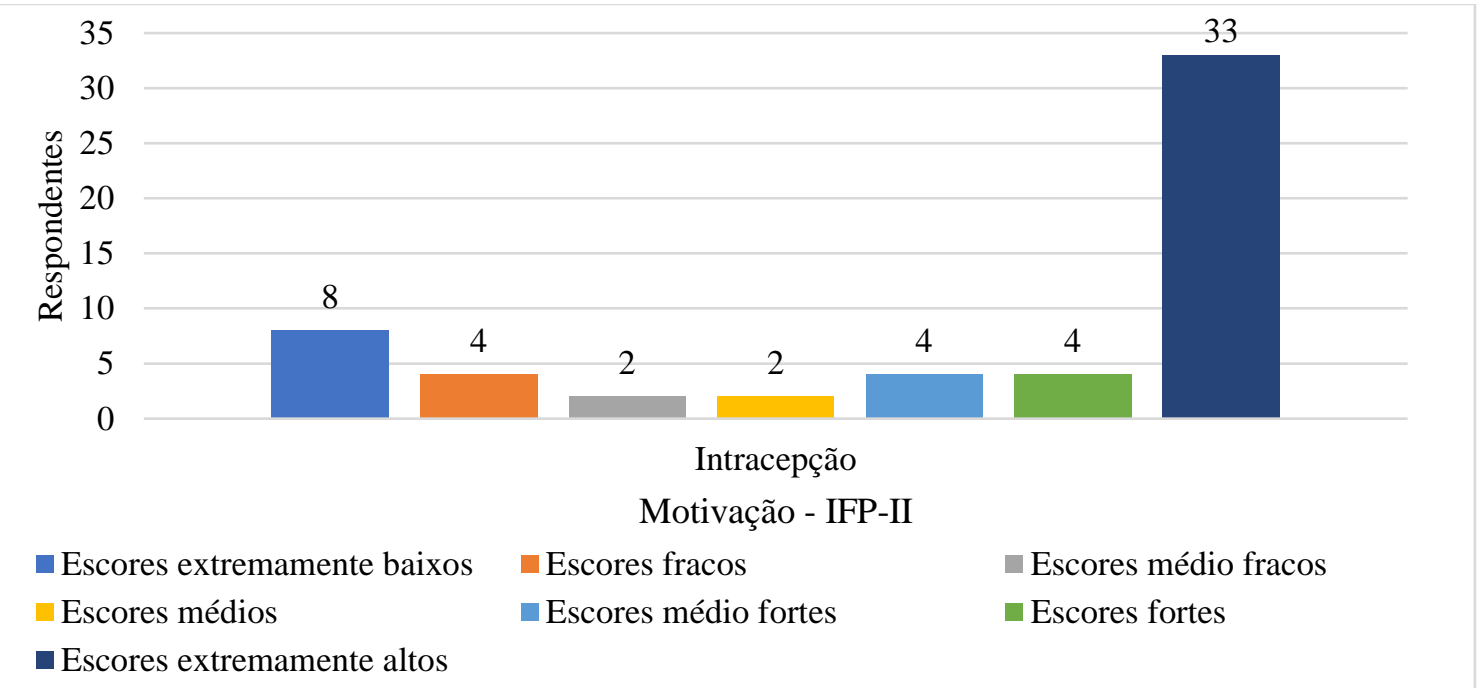

Figura 4. Resultados da Necessidade Intracepção agrupados pelos Escores

Para a competência Tomada de Decisão, a DCN prevê que o profissional de Psicologia deve estar apto a tomar decisões baseadas em evidências, ou seja em dados e fatos concretos (CNE, 2004). As tomadas de decisões não podem ser entendidas como algo advindo da intuição, senso comum ou feitas de forma impulsiva. Assim, apresentam-se contraditórios os resultados coletados por meio do IFP-II, que apesar de $80,8 \%$ dos discentes e $75 \%$ dos docentes concordarem com a posse da competência Tomada de Decisão, a média geral do escore da necessidade Intracepção foi relativamente alta (67,6\%). Como a Intracepção é uma necessidade oposta a competência da Tomada de Decisão era preferível que a maioria dos respondentes estivessem entre os escores extremamente baixos e os escores médio fracos, porém, como pode ser observado na Figura 4, não foi o que ocorreu, destacando-se o fato de que 33 dos 57 investigados apresentaram escore extremante alto para essa necessidade, que demonstra a predominância do comportamento de fazer julgamentos baseados em fantasias, sentimentos e desejos e, consequentemente, 
ignorar as condições concretas ao seu redor, que incluem as evidências científicas. Fazer a prática baseada em evidência é unir a boa ciência à prática profissional, é considerar as evidências científicas e refletir criticamente sobre sua aplicabilidade à prática clínica. Com a Intracepção, é mantida a tendência demonstrada pela Figura 1, de que os graduandos do décimo período, em sua maioria, estão focados em si, possuindo dificuldade de ir ao encontro do outro.

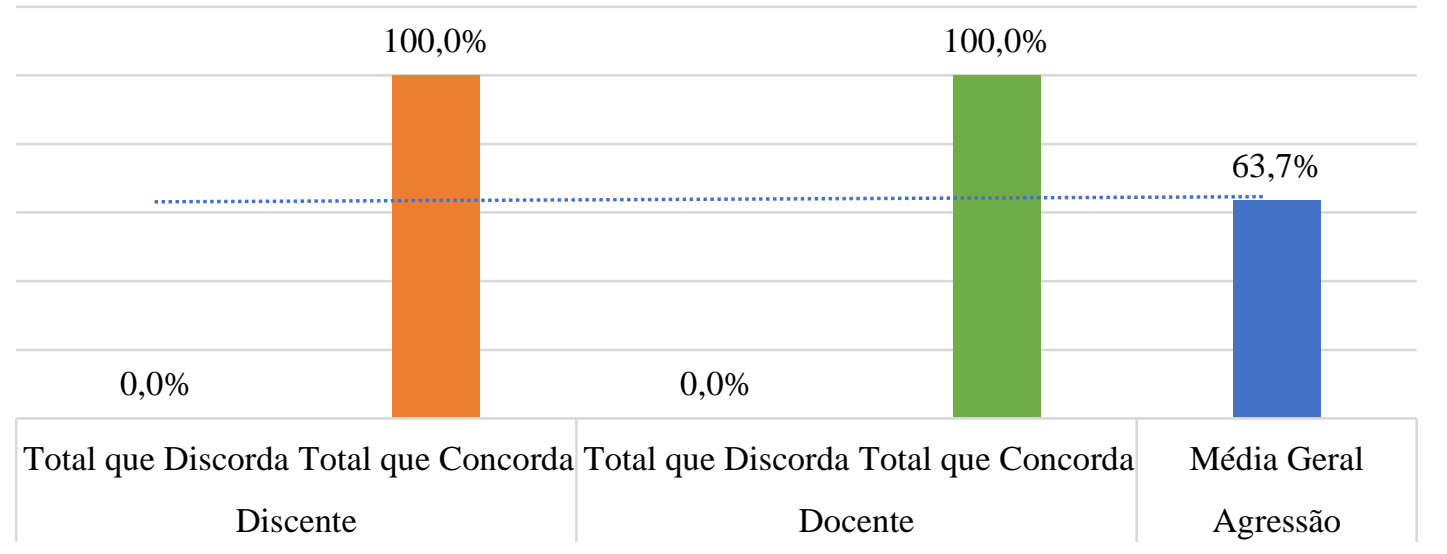

Figura 5. Comparativo referente à Competência Comunicação

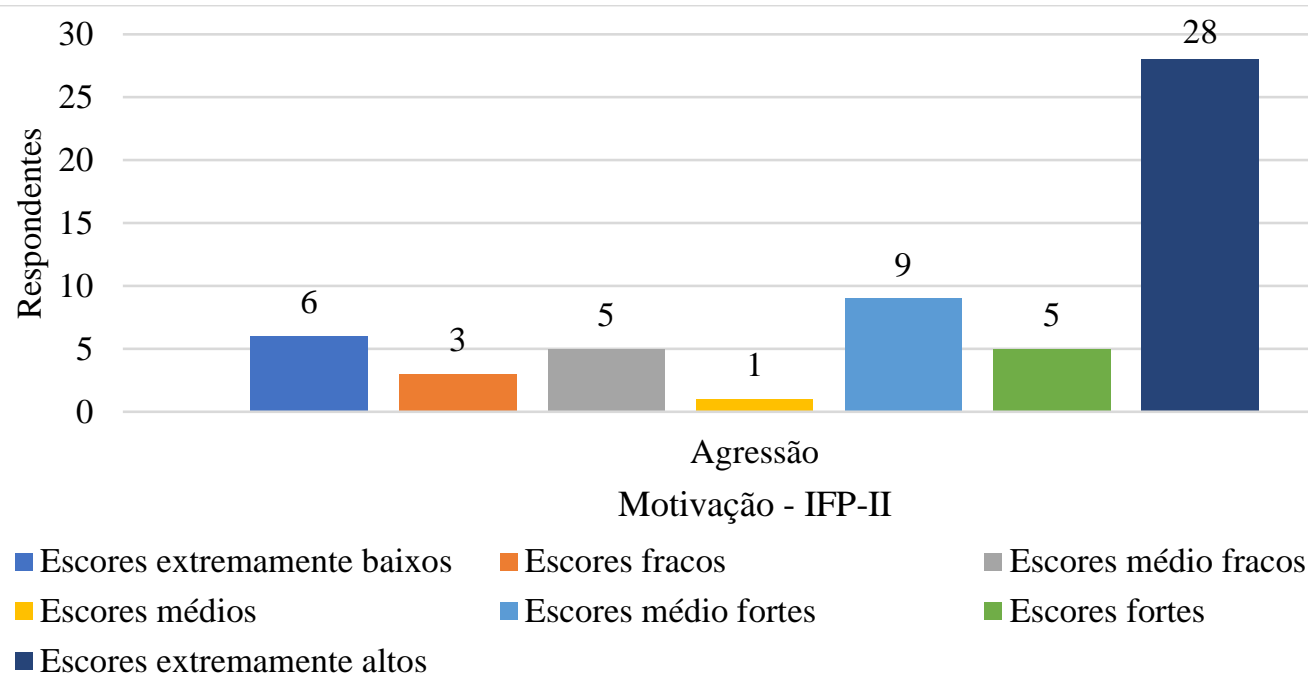

Figura 6. Resultados da Necessidade Agressão agrupados pelos Escores

Na Figura 5, que aborda sobre a competência Comunicação, constata-se que permanece o padrão de foco individualizado em detrimento da consideração do "universo" dos Outros. Apesar de unanimemente todos os discentes e docentes concordarem com a posse da competência Comunicação como auto percebida, ou percebida nos alunos, na realidade o IFP-II constata que a motivação psicológica de Agressão possui uma média de escore muito alta para os alunos investigados. Como a necessidade de Agressão é oposta à competência Comunicação, seus resultados precisariam estar entre os escores extremamente baixos e os escores médio fracos, o que a Figura 6 demonstra que não ocorreu. Dos 57 discentes, 28 apresentaram uma necessidade de Agressão extremamente alta, que, consequentemente, configura uma objeção à troca dialógica. A agressividade é totalmente incoerente com a competência da Comunicação que prevê a acessibilidade ao diálogo e interação (CNE, 2004), já que a agressão emerge da intolerância e da necessidade de superar com vigor e violência aqueles que se opõem a ele. 


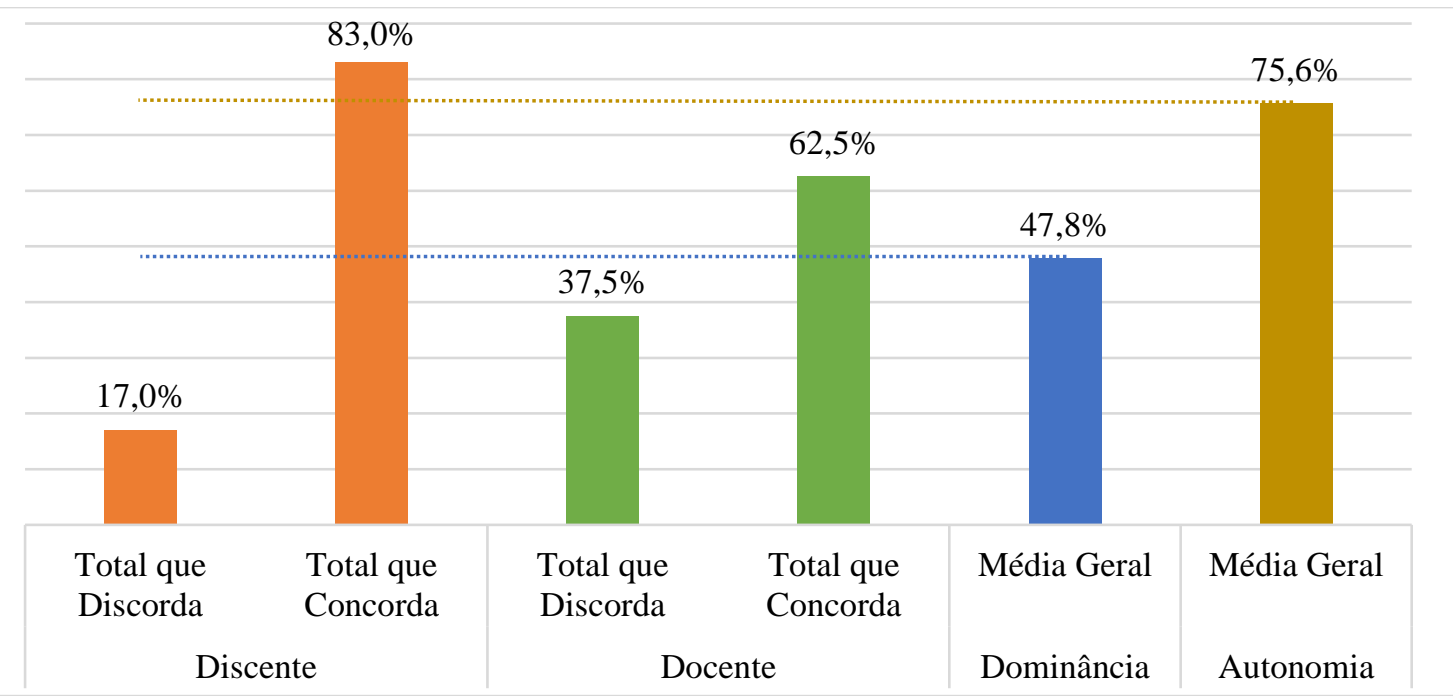

Figura 7. Comparativo referente à Competência Liderança

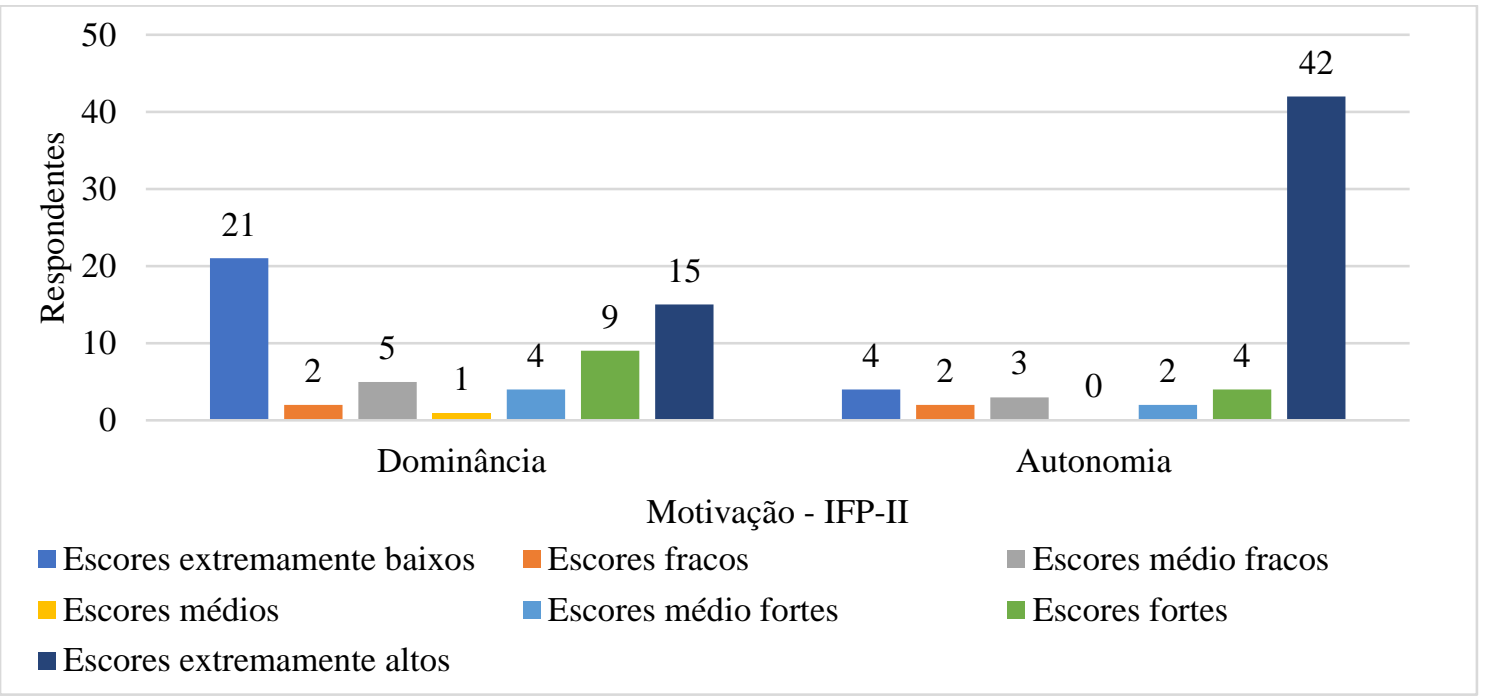

Figura 8. Resultados das Necessidades Dominância e Autonomia agrupados pelos Escores

Como pode ser visto na Figura 7, a competência Liderança pode ser associada a duas necessidades contempladas no IFP-II, e ambas precisam apresentar escore moderado (entre escore médio fraco e escore médio forte) para que a competência de Liderança esteja presente, são elas: Dominância e Autonomia. Deste modo, o resultado dos questionários, onde $83 \%$ (44 de 53) dos alunos percebem em si e $62,3 \%$ dos professores (5 de 8 ) percebem nos discentes a competência, pareceria coerente com a média do escore da necessidade de Dominância que apresentou uma média geral de $47,8 \%$. Entretanto, a Figura 8 demonstra que essa moderação irreal ocorre por que os resultados dos investigados se concentraram nos escores extremos, evidenciando que ou eles são altamente submissos ou altamente dominadores, sendo que os dois extremos são incompatíveis com a competência Liderança. Já para a necessidade de Autonomia, o resultado dos questionários é incoerente com a média geral do escore, que atingiu um valor extremamente alto de $75,6 \%$, destacando-se que 42 entre os 57 investigados possuem uma necessidade de Autonomia com escore extremamente alto, o que significa dizer que os discentes nutrem um grande apego à independência que dificulta o exercício da liderança, principalmente a democrática, e o trabalho em equipe multiprofissional como preconiza as DCN (CNE, 2004). 


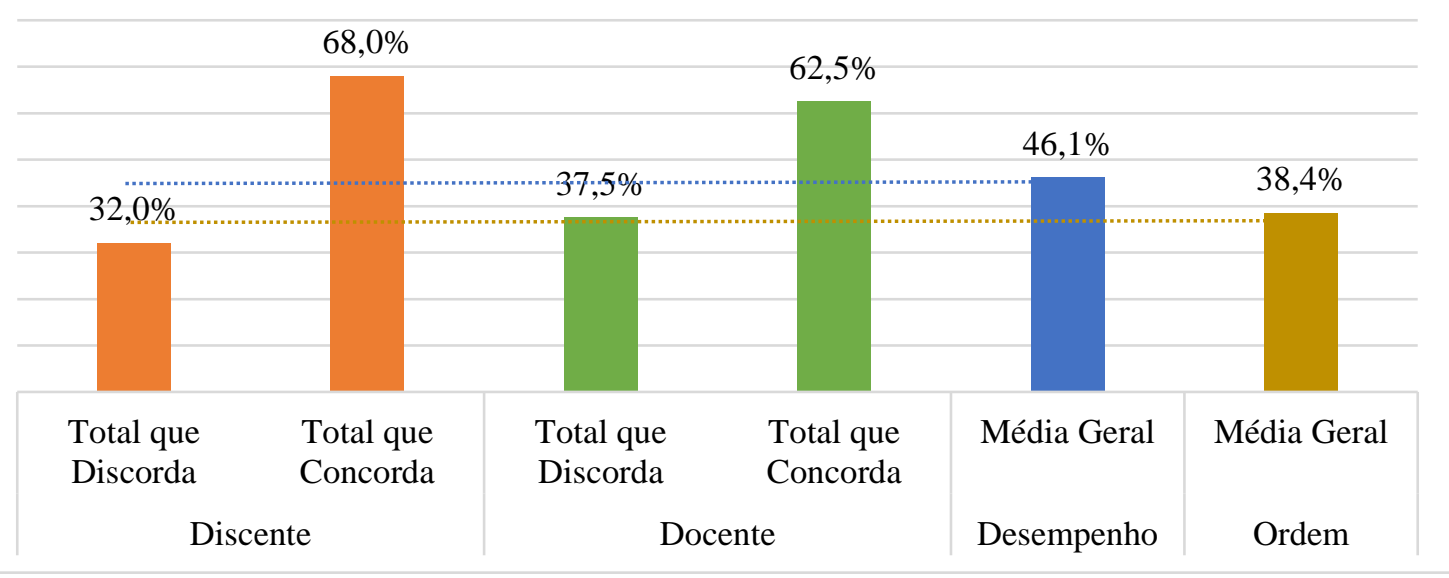

Figura 9. Comparativo referente à Competência Administração e Gerenciamento

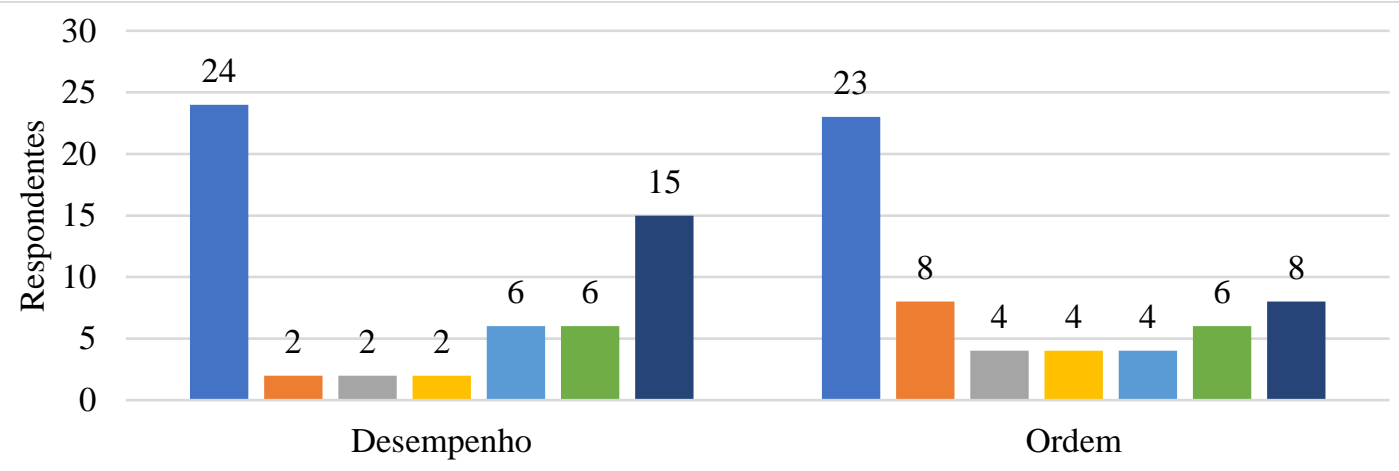

Motivação - IFP-II

$\begin{array}{lll}\square \text { Escores extremamente baixos } & \text { Escores fracos } & \text { Escores médio fracos } \\ \text { Escores médios } & \square \text { Escores médio fortes } & \text { Escores fortes } \\ \square \text { Escores extremamente altos } & \end{array}$

Figura 10. Resultados das Necessidades Desempenho e Ordem agrupados pelos Escores

Na Figura 9, observa-se que quando é comparado e analisado o resultado dos questionários em paralelo com as necessidades abordadas no IFP-II que são pré-requisito para a competência Administração e Gerenciamento, o resultado é altamente incoerente. As necessidades Desempenho e Ordem são essenciais para a competência em questão, mas, por mais que os discentes e os docentes percebam que ocorre a posse da aptidão para tomar iniciativa, administrar, gerenciar e serem empreendedores, gestores, empregadores e/ou líderes, na realidade notadamente a média do escore das duas necessidades ficou abaixo dos 50\%, correspondendo a $46,1 \%$ para Desempenho e $38,4 \%$ para Ordem. Por serem necessidades pré-requisito para a competência, o ideal era que os resultados dos escores para ambas se apresentassem entre os escores médio fortes e os escores extremamente altos. Porém, a Figura 10 evidencia que para as duas necessidades a maior parte dos resultados foram entre os escores extremante baixos e os escores médio fracos, com destaque para os escores extremamente baixos que apresentaram a maior ocorrência, sendo 24 discentes para a necessidade Desempenho e 23 para a necessidade Ordem. O que aponta que, além de não buscar soluções, nem manter altos padrões de desempenho, eles também não tendem a ser organizados (Leme et al., 2013), como é esperado para os detentores da competência Administração e Gerenciamento.

Quando é resgatado o dado de que essa competência foi a que mais teve abstenções, com um total de 6 alunos que não desejaram responder sobre a autopercepção em relação à competência, retoma-se a reflexão sobre o 
possível desconhecimento dos graduandos de que necessitam desenvolver essa competência dentro da graduação em Psicologia.

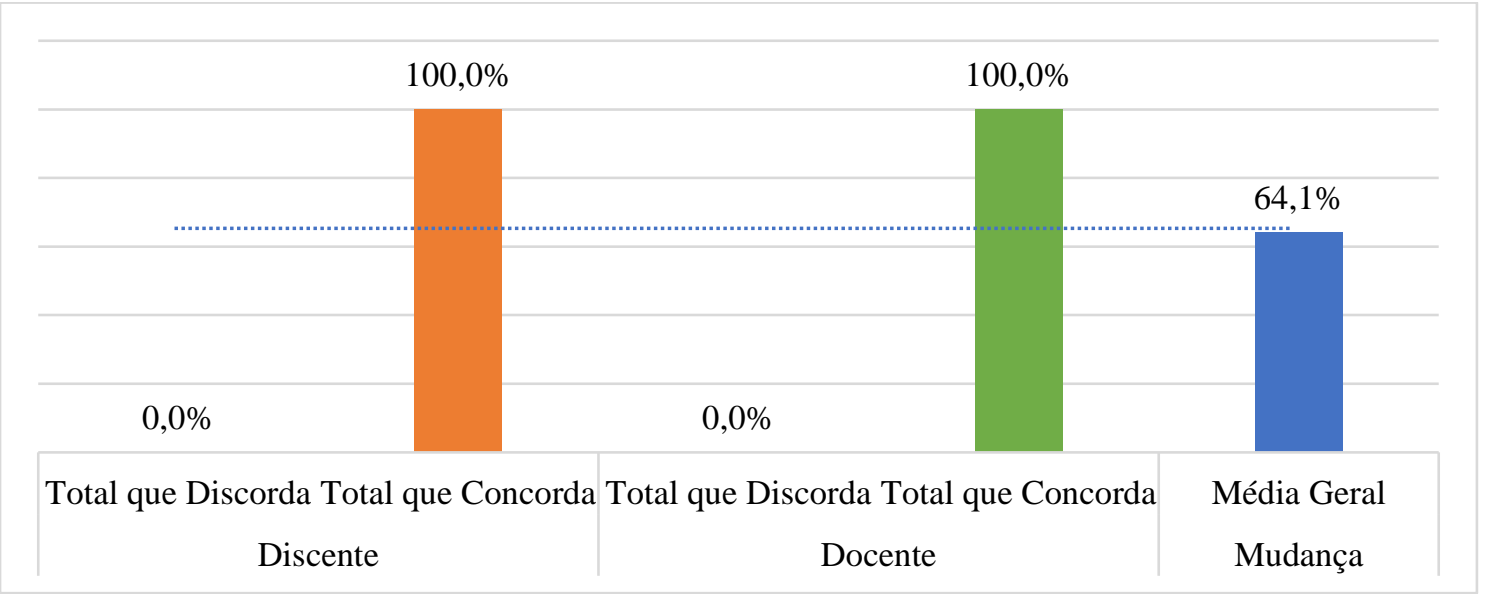

Figura 11. Comparativo referente à Competência Educação Permanente

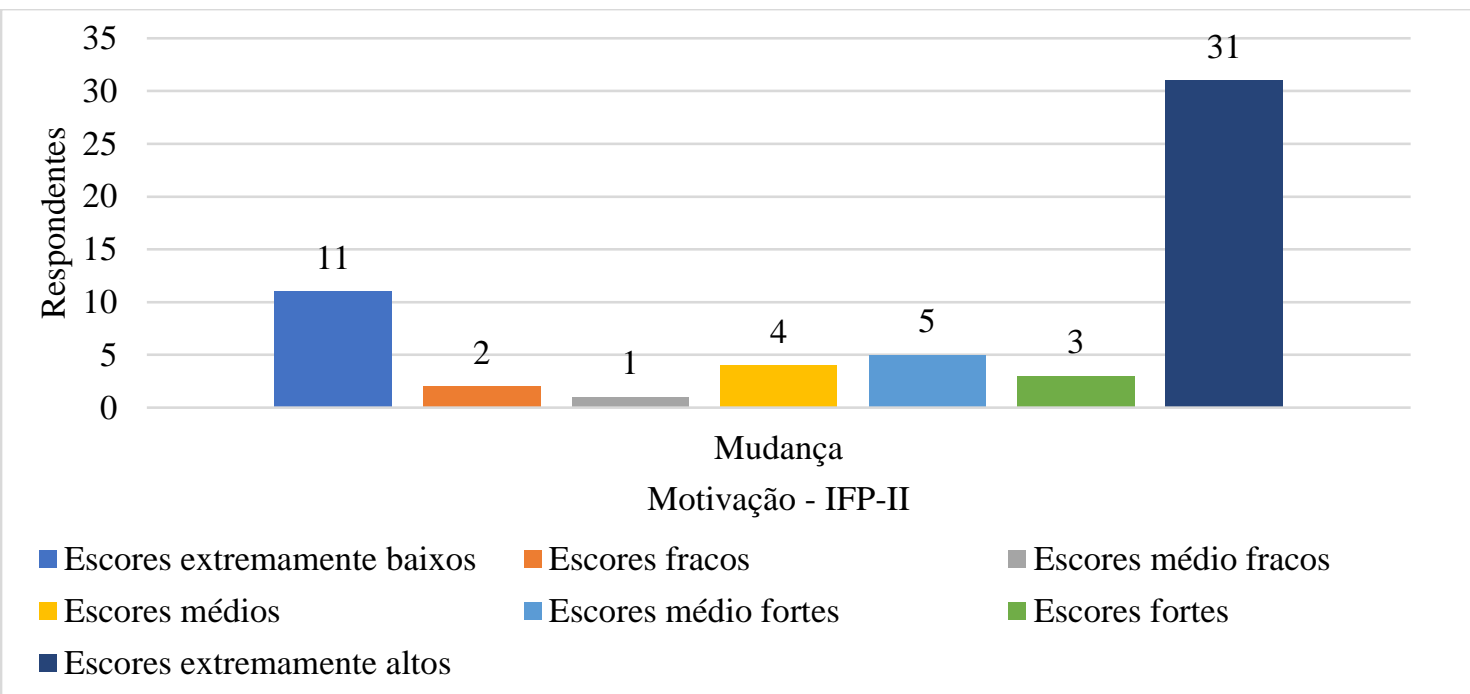

Figura 12. Resultados da Necessidade Mudança agrupados pelos Escores

Ao analisar a Figura 11 que expõe o comparativo da última competência, a de Educação Permanente, observa-se que os resultados obtidos nos questionários são minimamente distintos dos dados coletados com o IFP-II para a necessidade de Mudança, que é pré-requisito da competência. A Educação Permanente prevê uma flexibilidade para o profissional de Psicologia, que esteja sempre preparado para buscar melhores práticas e refletir sobre seu fazer diário $(\mathrm{CNE}$, 2004). O profissional que é avesso às mudanças, não pode ter a competência de Educação Permanente, por estar altamente engessado em suas convicções. É necessário que a prática reflexiva ocorra com a busca por evidências científicas (CFP, 2013). Algo que só será possível se existir a necessidade de Mudança.

Na Figura 11 constata-se que todos os alunos (total de 56) e professores (total de 8) que responderam a essa questão afirmam que esta competência está presente. Entretanto, a média do escore para a necessidade de Mudança é de 64,1\%. O resultado da necessidade pré-requisito não é tão alto como o resultado dos questionários para a competência, porém considera-se que refletem a possível existência da competência da Educação Permanente na maioria dos discentes. Algo que é evidenciado na Figura 12 em que se verifica 
o predomínio dos respondentes na faixa de escore desejada (entre escore médio forte e escore extremamente alto), com destaque para 31 discentes com escore extremamente alto.

\section{Discussão}

O tema escolhido é bastante discutido nas últimas décadas, devido à substituição do Currículo Mínimo pelas DCN como norteadoras da formação em nível de graduação do profissional de Psicologia. O que permitiu uma maior reflexão de uma prática comprometida socialmente, onde o Psicólogo deixa de ser visto como profissional isolado para ser inserido dentro de uma clínica ampliada que se dá por meio das práticas integrativas.

A resolução do Conselho Nacional de Educação (2004, 2011) afirma que as competências precisam ser desenvolvidas na formação do aluno, para que em sua prática ele seja capaz de atuar na profissão de Psicologia atendendo às demandas sociais, de acordo com as diferentes situações em que esteja inserido, problematizando e contextualizando sua prática. Isso nos dá a compreensão de que a formação precisa ser preparatória para a inserção do discente em seu campo de prática, para que assim esse futuro profissional desenvolva as competências mínimas necessárias para o exercício compromissado e reflexivo. Deste modo, existe uma demanda por estudos que avaliem se as transformações das últimas décadas na formação e na atuação do psicólogo está atingindo o que é previsto pelas DCN (Bardagi, Bizarro, De Andrade, Audibert, \& Lassance, 2008).

Por meio dos resultados deste estudo, obteve-se um maior conhecimento do perfil dos estudantes evidenciando que da amostra de discentes graduandos do décimo período do curso de Psicologia da instituição selecionada, no momento da coleta dos dados, a maioria não possuía cinco das seis Competências e Habilidades Gerais previstas nas DCN, sendo elas para: Atenção à Saúde, Tomada de Decisão, Comunicação, Liderança, e Administração e Gerenciamento. Tais resultados estariam relacionados a que existe em boa parte dos discentes: pouca necessidade de Assistência, alta Intracepção, alta necessidade de Agressão, extrema Submissão ou extrema Dominação, exacerbada necessidade de Autonomia e pouca motivação para o Desempenho e para a Ordem. Assim, destaca-se que a amostra discente evidenciou que, possivelmente, a maioria possuísse apenas a competência para a Educação Permanente, mesmo com certo grau de engessamento e rejeição à Mudança por parte de alguns alunos (Leme et al., 2013). Como as competências gerais são compreendidas como base comum onde o desenvolvimento das competências específicas irá se alicerçar (CFP, 2018), consequentemente infere-se um possível prejuízo generalizado na formação e atuação desta amostra investigada.

Neste ponto é importante refletir que mesmo a competência Educação Permanente pode apresentar prejuízo em sua funcionalidade. Pois, ao ser analisada em conjunto com a alta predominância da necessidade Intracepção, que já dificulta a competência da Tomada de Decisão por não permitir que as decisões sejam baseadas em evidências cientificas, é possível questionar quais serão os critérios utilizados para o exercício da competência Educação Permanente, visto que a Intracepção direciona os investigados a decidir por mudanças sustentadas em intuição, senso comum, fantasias e desejos (Leme et al., 2013), e não na melhor prática baseada em evidências, inclusive quanto ao processo de constante requalificação do profissional. $\mathrm{O}$ uso do "bom senso" como parâmetro para tomada de decisões já havia sido evidenciado em pesquisa anterior (Ferrarini et al., 2016).

O processo de tomada de decisão no exercício da competência de Educação Permanente tem que ir para além da motivação para Mudança, quando se estabelece a exigência de que ele ocorra apoiado em bases científicas (CFP, 2013). A prática baseada em evidências só é possível quando por meio das competências do profissional é considerada a melhor evidência empírica disponível aliada às 
particularidades contingenciais (Leonardi \& Meyer, 2015). O que novamente evidencia que a graduação em psicologia é o local propício para o desenvolvimento destas competências gerais que além de basearem a atuação do psicólogo também estão interligadas entre si.

O fato de a ciência psicológica ser multifacetada, torna ainda mais essencial o desenvolvimento dessas competências gerais de maneira interdependente. Como foi levantado por estudo anterior, as divergências da ciência psicológica muitas vezes causam entre os discentes a dificuldade em reconhecer uma identidade única para sua futura profissão (Ferrarini et al., 2016). Portanto, se o processo ensino-aprendizagem falhar em desenvolver uma prática reflexiva que utilize o repertório comportamental permeado pelas competências gerais, o psicólogo pode ser direcionado a contribuir para a banalização da profissão, desconsiderando as evidências científicas e afastando-se do seu lugar de protagonismo científico enquanto promotor de saúde.

A diversidade da Psicologia não pode ser considerada um aspecto negativo, pois para atuar com a complexidade dos fenômenos psicológicos é essencial se apoiar nesses múltiplos saberes, em que a educação permanente ocorre por meio dos questionamentos e inovações. Assim, as competências gerais permitirão que o graduando esteja capacitado para exercer sua flexibilidade com o uso de evidências científicas, articulando em equipes interdisciplinares e assumindo a liderança da ciência psicológica em qualquer contexto em que esteja inserido (Ferrarini et al., 2016), promovendo a saúde integral, compromissado com a transformação social (Poppe \& Batista, 2012). Portanto, dentro da formação continuada é imprescindível que haja uma prática reflexiva, desde a graduação, que remeta sempre a análise dos impactos que as intervenções promovem individualmente e coletivamente. Este seria o primeiro passo para aproximar a prática da teoria, superando o puro tecnicismo (CFP, 2013).
O psicólogo como profissional interventor de saúde em qualquer contexto em que esteja inserido (CFP, 2018), necessita estar apto a atuar para a Atenção à Saúde. As competências gerais são interdependentes e tornam-se essenciais para a clínica ampliada, que assume a premissa da Integralidade e que compreende a interdisciplinaridade como estratégia de ação. Assim, para garantir os princípios da integralidade, da territorialidade e da universalidade, que baseiam o cuidado multidimensional dos sujeitos singulares, as competências gerais são instrumentos que possibilitam o atendimento atento e reflexivo às demandas reais, feito dialogicamente por equipes interdisciplinares (Giacomozzi, 2012).

A dificuldade para o trabalho em equipe também já havia sido constatada em estudos anteriores (Ferrarini et al., 2016; Poppe \& Batista, 2012). O não desenvolvimento das competências de Comunicação e Liderança levantam a reflexão de que, apesar da proposta de integração das DCN, os cursos de graduação em Psicologia parecem permanecer isolados em suas práticas cotidianas, tanto dos outros cursos de graduação, quanto do contexto social em geral. O que prejudica consideravelmente a formação do psicólogo como promotor de saúde que considera o sujeito integralmente.

Assim, cabe destacar a relevância da expansão dos cenários de ensinoaprendizagem. O conhecimento tácito deve ser construído dentro dos mais variados contextos de atuação em que o psicólogo pode estar inserido, inclusive com a prática integrada com profissionais e discentes de outras graduações (Poppe \& Batista, 2012). O que, sempre de forma supervisionada, deve ocorrer desde o início da formação em Psicologia.

Outro ponto de discussão a ser destacado é a incoerência dos resultados dos questionários de percepção e de autopercepção quando comparados com os resultados do IFPII. Essas disparidades podem evidenciar que existe realmente uma necessidade de que o objetivo do desenvolvimento das competências gerais seja amplamente discutido pelos discentes e docentes na graduação, para que 
possam buscar estratégias de ensinoaprendizagem de forma mais direcionada.

As inferências realizadas sobre os dados coletados possuem limitações. $\mathrm{O}$ teste psicológico escolhido traz referências sobre aspectos motivacionais dos sujeitos, permitindo a comparação da coerência de suas existências com a posse das competências previstas nas DCN. Assim, é interessante propor que, para estudos futuros, ocorra a aplicação de mais de um teste psicológico, de modo que seja assumida uma maior confiabilidade para os comparativos que possam ser construídos.

Tendo o exposto em mente, os resultados encontrados estão de acordo com a literatura que embasa esse estudo, que afirma haver uma grande defasagem entre o que preconizam as DCN e o que realmente está sendo desenvolvido das competências no cotidiano das graduações em Psicologia (Bastos et al., 2010; CFP, 2013).

\section{Conclusão}

Foi alcançado o objetivo de verificar a presença das competências e habilidades gerais, previstas nas Diretrizes Curriculares Nacionais dos Cursos de graduação em Psicologia, em graduandos do décimo período. E foi possível concluir que o presente estudo tem relevância não apenas para a comunidade acadêmica, mas também para a população em geral, tendo em vista que o psicólogo é integrante de um saber em saúde que passa pelo conhecimento integrado, pautado pela clínica ampliada, que supõe o cuidado ao homem em sua integralidade.

Conhecer os resultados produzidos nos cursos de graduação em Psicologia, no que diz respeito às competências e habilidades gerais previstas pelas DCN, permitiu saber se a amostra investigada de formandos estaria preparada para cumprir seu compromisso social de atender às demandas. Por conta da visibilidade trazida pelos resultados desta pesquisa é possível construir estratégias de ensino-aprendizagem focadas em suprir as lacunas encontradas. Para tanto, é preciso que haja o diálogo com trocas de experiências entre os docentes e a escuta dos discentes sobre suas expectativas em relação ao desenvolvimento dessas competências. Em seguida, podem ser adotadas estratégias como, por exemplo, através do desenvolvimento de metodologias ativas que integrem graduandos de diversos cursos e diversos campos de saber, para que seja promovida a transdisciplinaridade e o uso da prática reflexiva e baseada em evidências inserida na comunidade como didática do cotidiano das salas de aula desde os primeiros períodos da graduação.

Por ser um estudo transversal, que corresponde a um grupo específico de pessoas, as pesquisadoras consideram que o resultado do estudo pode ter limitações para sua generalização, e, também, não é possível afirmar que as competências identificadas tenham sido desenvolvidas durante o curso, sendo necessário para tanto um estudo longitudinal que comparasse os mesmos sujeitos, antes e depois de terem sido expostos a grade curricular planejada no projeto pedagógico do curso. Deste modo, a possibilidade de conclusão se limita a dizer se a competência estava presente ou não no fim do curso e, consequentemente, se ela não estava presente, é correto afirmar que não foi desenvolvida. Mesmo diante das limitações levantadas, o estudo não deixa de ser relevante como primeiro passo em futuros estudos longitudinais mais aprofundados, inclusive com o uso de dois ou mais testes psicológicos que estenderiam a confiabilidade dos dados obtidos.

O presente estudo, pode ser considerado uma ponte para a compreensão do processo de ensino-aprendizagem por meio dos resultados apurados. E propõe que haja desdobramentos sobre o estudo atual, de modo que, além dos resultados analisados serem utilizados para melhoria das práticas educativas atuais, também sejam desenvolvidas novas pesquisas que permitam dados mais aprofundados do processo de ensino-aprendizagem no ensino superior, inclusive longitudinalmente, 
ultrapassando a limitação do resultado transversal.

\section{Referências}

Bardagi, M. P, Bizarro, L., de Andrade, A. M. J., Audibert, A., \& Lassance, M. C. P. (2008). Avaliação da formação e trajetória profissional na perspectiva de egressos de um curso de psicologia. Psicologia: ciência e profissão, 28(2), 304-315. Recuperado de http://pepsic.bvsalud.org/scielo.php?script= sci_arttext\&pid=S141498932008000200007\&lng=pt\&tlng=pt.

Bastos, A. V. B., Gondim, S. M. G., \& Borges-Andrade, J. E. A. (2010). O psicólogo brasileiro: sua atuação e formação profissional. O que mudou nas últimas décadas?. In O. H. Yamamoto, \& A. L. F. Costa (Orgs.), Escritos sobre a profissão de psicólogo no Brasil (pp. 257271). Natal, RN: EDUFRN.

Brasileiro, T. S. A., \& Souza, M. P. R. (2010). Psicologia, diretrizes curriculares e processos educativos na Amazônia: um estudo da formação de psicólogos. Psicologia Escolar e Educacional, 14(1), 105-120. doi: 10.1590/S1413-85572010000100012

Conselho Nacional de Educação [CNE]. Câmara de Educação Superior. (2004). Resolução 8/2004: institui as Diretrizes Curriculares Nacionais para os cursos de graduação em Psicologia. Brasília: Diário Oficial da União.

Conselho Nacional de Educação [CNE]. Câmara de Educação Superior. (2011). Resolução 5/2011: institui as Diretrizes Curriculares Nacionais para os cursos de graduação em Psicologia, estabelecendo normas para o projeto pedagógico complementar para a Formação de Professores de Psicologia. Brasília: Diário Oficial da União.

Conselho Federal de Psicologia [CFP]. (2013). Contribuições do Conselho Federal de Psicologia à discussão sobre a formação da(o) psicóloga (o). Brasília: Conselho Federal de Psicologia.
Conselho Federal de Psicologia [CFP]. Associação Brasileira de Ensino de Psicologia. Federação Nacional de Psicólogos. (2018). Ano de Formação em Psicologia - 2018. Brasília: Conselho Federal de Psicologia

Ferrarini, N. L., Camargo, D., Albanese, L., Pan, M. A G. S., \& Bulgacov, Y. L. M. (2016). Formação do Psicólogo Brasileiro: impasses e desafios. Revista INFAD de Psicología: International Journal of Developmental and Educational Psychology, 2(1), 271-282. doi: 10.17060/ijodaep.2016.n1.v2.149

Giacomozzi, A. I. (2012). A inserção do psicólogo na Estratégia de Saúde da Família e a transição do paradigma em Saúde. Psico, 43(3), 298-308. Recuperado de

http://revistaseletronicas.pucrs.br/ojs/index. php/revistapsico/article/view/7212/0

Kubo, O. M., \& Botomé, S. P. (2001). Ensinoaprendizagem: uma interação entre dois processos comportamentais. Interação em Psicologia, 5(1). doi: 10.5380/psi.v5i1.3321

Leme, I. F. A. S., Rabelo, I. S., \& Alves, G. A. S. (2013). IFP II - Inventário Fatorial de Personalidade. São Paulo: Casa do Psicólogo.

Leonardi, J. L., \& Meyer, B. (2015). Prática Baseada em Evidências em Psicologia e a História da Busca pelas Provas Empíricas da Eficácia das Psicoterapias. Psicologia: Ciência e Profissão, 35(4), 1139-1156. doi: 10.1590/1982-3703001552014

Lima, V. C., \& Souza, R. T. (2014). Formação humana e competências: o debate nas diretrizes curriculares de psicologia. Psicologia \& Sociedade, 26(3), 792-802. doi: $10.1590 /$ S010271822014000300027

Poppe, A. R. S., \& Batista, S. H. S. S. (2012). Formação em Psicologia no contexto das diretrizes curriculares nacionais: uma 
discussão sobre os cenários da prática em saúde. Psicologia: Ciência e Profissão, 32(4), 986-999.

doi: 10.1590/S1414-98932012000400016

Santos, G. V., Kienen, N., Viecili, J., Botomé, S., \& Kubo, O. (2009). "Habilidades" e "Competências" a desenvolver na capacitação de psicólogos: uma contribuição da análise do comportamento para o exame das diretrizes curriculares. Interação em Psicologia,
13(1), 131-145. doi:10.5380/psi.v13i1.12279

Seixas, P. S. (2012). A formação graduada em Psicologia no Brasil: reflexão sobre os principais dilemas em um contexto pós$D C N$ (Tese de Doutorado). Universidade Federal do Rio Grande do Norte, Natal. Recuperado de http://repositorio.ufrn.br/jspui/handle/1234 $\underline{56789 / 17401}$

\section{Dados sobre os autores:}

- Lívia Teixeira Costa Silva: Faculdade INESP / IEPSIS - Instituto Educacional Pesquisa em Saúde e Inclusão Social. Psicóloga (CESMAC), Administradora de Empresas (UFAL), Especialista em Gestão de Recursos Humanos (FIC / UNIFAL).

- Luana Valeria de Souza Chagas: Centro Universitário CESMAC, Psicóloga (CESMAC).

- Edna Pereira Gomes de Morais: Universidade Estadual de Ciências da Saúde de Alagoas UNCISAL. Docente do Centro de Ciências da Saúde/Núcleo de propedêutica e terapêutica, Fonoaudióloga (UNICAP), Mestrado em Ciências (Distúrbios da Comunicação Humana) e Doutorado em Ciências (Saúde baseada em evidências) (UNIFESP).

- Layse Veloso de Amorim Santos: Centro Universitário CESMAC. Docente do Centro Universitário CESMAC, Psicóloga do Centro de Recuperação Educacional Nutricional CREN, Psicóloga (UFAL), Formação em medicina psicossomática (ABMP - Aracaju), Mestrado e doutorado em Ciências da Saúde (UFAL). 